\title{
Integrated transcriptome analysis of human iPS cells derived from a fragile $X$ syndrome patient during neuronal differentiation
}

\author{
Ping $\mathrm{Lu}^{1 \dagger}$, Xiaolong $\mathrm{Chen}^{2 \dagger}$, Yun Feng ${ }^{1 \dagger}$, Qiao Zeng ${ }^{1}$, Cizhong Jiang ${ }^{2}$, Xianmin $\mathrm{Zhu}^{2 *}$, \\ Guoping Fan $^{2,3 * *} \&$ Zhigang Xue ${ }^{1,4,5^{* * *}}$ \\ ${ }^{1}$ Tongji Stem Cell Research Center, Tongii University School of Medicine, Shanghai 200092, China; \\ ${ }^{2}$ Tongji University, School of Life Sciences and Technology, Shanghai 200092, China; \\ ${ }^{3}$ Department of Human Genetics, David Geffen School of Medicine, University of California Los Angeles, Los Angeles CA 90095, USA; \\ ${ }^{4}$ Translational Center for Stem Cell Research, Tongji Hospital, Department of Regenerative Medicine, Tongji University School of Medicine, \\ Shanghai 200065, China; \\ ${ }^{5}$ Tongji University Suzhou Institute, Suzhou 215101, China
}

Received June 30, 2016; accepted September 5, 2016; published online October 11, 2016

\begin{abstract}
Fragile X syndrome (FXS) patients carry the expansion of over 200 CGG repeats at the promoter of fragile X mental retardation 1 (FMR1), leading to decreased or absent expression of its encoded fragile X mental retardation protein (FMRP). However, the global transcriptional alteration by FMRP deficiency has not been well characterized at single nucleotide resolution, i.e., RNA-seq. Here, we performed in-vitro neuronal differentiation of human induced pluripotent stem (iPS) cells that were derived from fibroblasts of a FXS patient (FXS-iPSC). We then performed RNA-seq and examined the transcriptional misregulation at each intermediate stage during in-vitro differentiation of FXS-iPSC into neurons. After thoroughly analyzing the transcriptomic data and integrating them with those from other platforms, we found up-regulation of many genes encoding TFs for neuronal differentiation (WNT1, BMP4, POU3F4, TFAP 2C, and PAX3), down-regulation of potassium channels (KCNA1, KCNC3, KCNG2, KCNIP4, KCNJ3, KCNK9, and $K C N T 1$ ) and altered temporal regulation of SHANK1 and NNAT in FXS-iPSC derived neurons, indicating impaired neuronal differentiation and function in FXS patients. In conclusion, we demonstrated that the FMRP deficiency in FXS patients has significant impact on the gene expression patterns during development, which will help to discover potential targeting candidates for the cure of FXS symptoms.
\end{abstract}

fragile X syndrome, induced pluripotent stem cells, neuronal differentiation, transcriptome

Citation: $\quad$ Lu, P., Chen, X., Feng, Y.,Zeng, Q., Jiang, C., Zhu, X., Fan, G., and Xue, Z. (2016). Integrated transcriptome analysis of human iPS cells derived from a fragile X syndrome patient during neuronal differentiation. Sci China Life Sci 59, 1093-1105. doi: 10.1007/s11427-016-0194-6

\section{INTRODUCTION}

Fragile X syndrome (FXS) is a common hereditary disorder associated with an array of intellectual limitations and

$\dagger$ Contributed equally to this work

*Corresponding author (email: xianminzhu@hotmail.com)

**Corresponding author (email: gfan@mednet.ucla.edu)

***Corresponding author (email: xuezg@tongji.edu.cn) emotional disabilities, and is also referred to as the most frequent monogenic cause of autism. In FXS patients, the CGG repeats at the $5^{\prime}$ untranslated region (5' UTR) of fragile $\mathrm{X}$ mental retardation 1 (FMRI) are dramatically increased ( $>200)$ compared to the healthy individuals. This trinucleotide expansion results in many epigenetic alterations including DNA hypermethylation and histone modifications, which ultimately silences the expression of FMR1 (Bagni et al., 2012). Fragile X mental retardation protein (FMRP), 
encoded by $F M R 1$, is ubiquitously expressed in many tissues, especially abundant in brain and testes (Devys et al., 1993). In the nervous system, loss of FMRP elevates the protein synthesis in the brain (Laggerbauer et al., 2001; Qin et al., 2005), weakens the synaptic strength and affects dendritic spines (Cruz-Martin et al., 2010; Pan et al., 2010; Pfeiffer and Huber, 2007), which therefore affects many different pathways, e.g., impairing metabotropic glutamate receptor (mGluR)-mediated signaling (Bear et al., 2004), reducing GABAergic transmission (D'Hulst and Kooy, 2007) and enhancing mTOR signaling (Sharma et al., 2010). The function of FMRP in cytoplasm was well characterized as a selective RNA-binding protein that negatively regulates the translation of the target mRNAs for presynaptic, postsynaptic proteins, and interestingly, many transcriptional factors (Ascano et al., 2012; Auerbach et al., 2011; Darnell et al., 2011; Kao et al., 2010; Lu et al., 2004; Muddashetty et al., 2007; Osterweil et al., 2010; Pfeiffer and Huber, 2007). FMRP also comprises the nuclear export signal (NES) and nuclear localization signal (NLS) domains and shuttles between the nucleus and cytoplasm (Eberhart et al., 1996; Feng et al., 1997; Sittler et al., 1996). Since it functions as a chromatin-binding protein responding to the DNA damage (Alpatov et al., 2014), it is very likely that FMRP may directly modulate the transcription in the nucleus. Although some microarray-based gene expression profiling data were generated from $F m r l$ null mice (D'Agata et al., 2002), FXS patients' lymphoblastoid cells (Bittel et al., 2007), and FXS patient derived iPS cells (Halevy et al., 2015), RNA-seq with higher throughput and resolution is urgently needed to dissect the transcriptional perturbation evoked by FMRP deficiency.

Several animal models have been created to study FXS. Fmr1 null mouse is one of the most successful mammalian models recapitulating the phenotypes of human FXS patients, such as abnormalities in synaptogenesis, synaptic structures and functions (The Dutch-Belgian Fragile X Consorthium, 1994). Of particular interest, researchers also generated the mouse model that carries specific mutation found in human FXS patients, i.e. I340N (Zang et al., 2009). Fruitful genetic rescue efficacy has been achieved in mouse models by targeting key molecules in different pathways, i.e., mGluR (Dolen et al., 2007; Lindemann et al., 2011; Michalon et al., 2012), amyloid $\beta$-protein precursor (A $\beta$ PP) (Westmark et al., 2011), mTOR (Auerbach et al., 2011), p21-activated kinase (PAK) (Hayashi et al., 2007), and protein tyrosine phosphatase (STEP) (Goebel-Goody et al., 2012). However, the mouse models have obvious limitations. For example, the transgenic mice do not carry the trinucleotide expansion. Uncontrollable variations such as age and genetic background influence the interpretation of different experimental settings. Recent progress in FXS human embryonic stem (ES) cells and iPS cells has overcome the drawbacks of the mouse models, which offers us a great tool to understand the pathogenic mechanisms in absence of FMRP (Eiges et al., 2007; Huang and Fu, 2014; Sheridan et al., 2011; Telias et al., 2013; Wu et al., 2007).

As stated above, the aberrant developmental phenotypes in FXS patients may be partly caused by a global disturbance of transcriptional regulation due to FMRP deficiency, which still remains unknown yet. To test this hypothesis, we obtained and examined a FXS-iPSC cell line (a kind gift from Dr. Philip H. Schwartz) from the fibroblasts of a FXS patient with expanded CGG repeats on the FMR1 promoter (Brick et al., 2014). We then differentiated FXS-iPSC, along with a healthy iPS cell line HDF2-iPSC as control, into post-mitotic neurons through different stages, i.e., iPSC aggregates (IA), neuroepithelia (NE), neuroepithelia aggregates (NA). After analyzing total 200 million mapped reads of RNA-seq data from the RNA collected at 4 different stages for each cell line, we found total 1,559 differentially expressed (DE) genes between FXS-iPSC and HDF2-iPSC during the neuronal differentiation. At the neuron stage, the genes related to early neuronal differentiation (e.g., WNT1, BMP4, and POU3F4) are up-regulated while many genes essential for neuronal functions such as potassium channels (KCNA1, KCNC3, KCNG2, $K C N I P 4, K C N J 3, K C N K 9$, and $K C N T 1)$ are down-regulated, which implied that FXS-iPSC derived neurons are immature and have impaired function compared to the mature neurons. In addition, we discovered the disruption of spatiotemporal regulation of some important neuronal factors, i.e., SHANK1 and NNAT. Our study, for the first time, revealed the altered transcriptome in patient-derived FXS-iPSC at different developmental stages by high-throughput RNA-seq, which will lead to recognition of the function of FMRP in direct/indirect transcriptional regulation. The genes which we characterized as important for neuronal differentiation and development will aid in the discovery of novel therapeutics for FXS in the future.

\section{RESULTS}

\section{Neuronal differentiation of FXS-iPSC}

We obtained a FXS-iPSC cell line (named SC128) from Dr. Philip H. Schwartz at Children's Hospital of Orange County, USA (Brick et al., 2014). This cell line has been stably and homogenously expanded for over 28 passages and kept maintaining ESC-like morphology (data not shown). All iPSC clones had typical characteristics of human pluripotent stem cells indicating successful reprogramming (data not shown). Using Asuragen Amplide X FMR1 PCR Kit, we found that there are 236 CGG repeats at the 5' UTR of FMR1 in FXSiPSC, whereas 36 in the control HDF2-iPSC (Figure S1 A and $B$ in Supporting Information). The expression of FMRP was not detected in the FXS-iPSC compared to the WT control HDF2-iPSC (Figure 1B, Figure S1C in Supporting Information). 


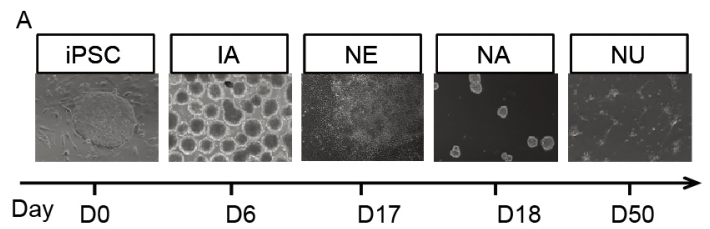

B iPSC stage

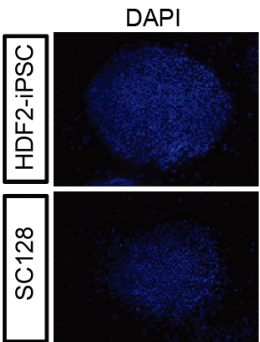

DAPI

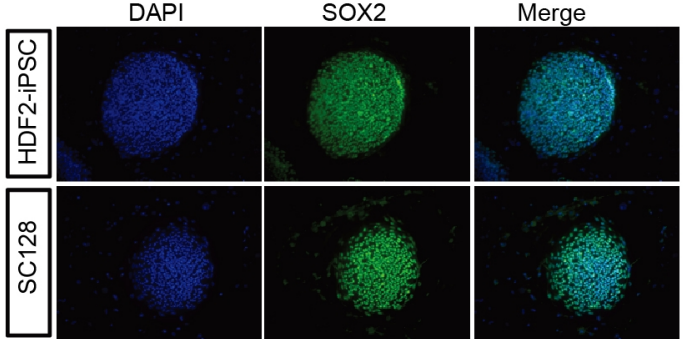

API

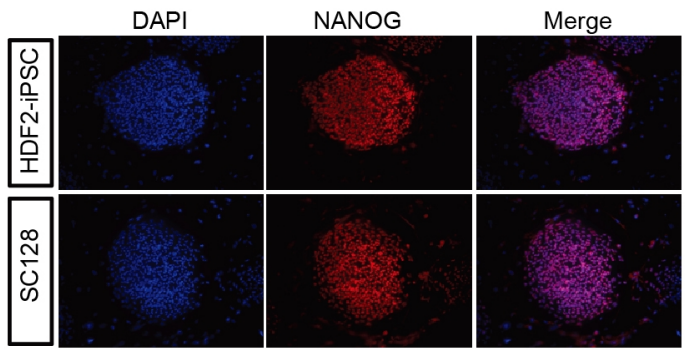

C NE stage

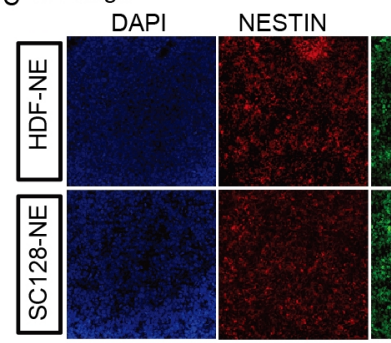

SOX1 Merge
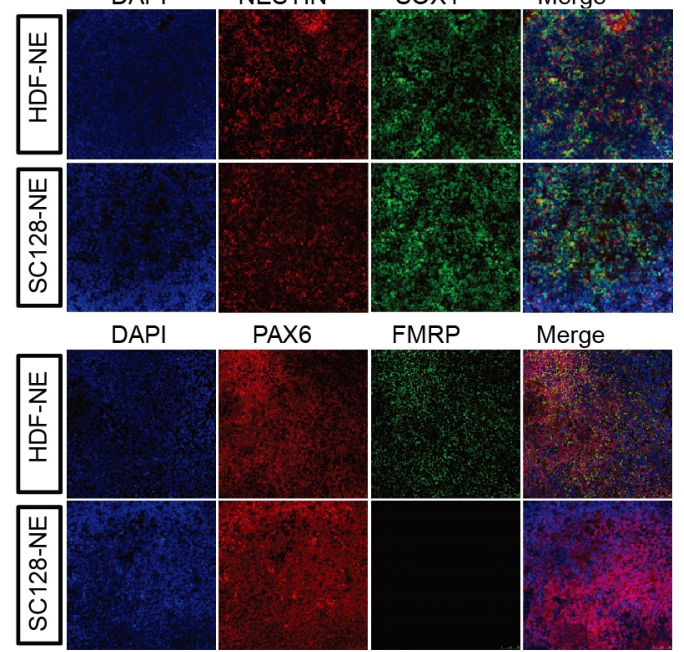

D NU stage
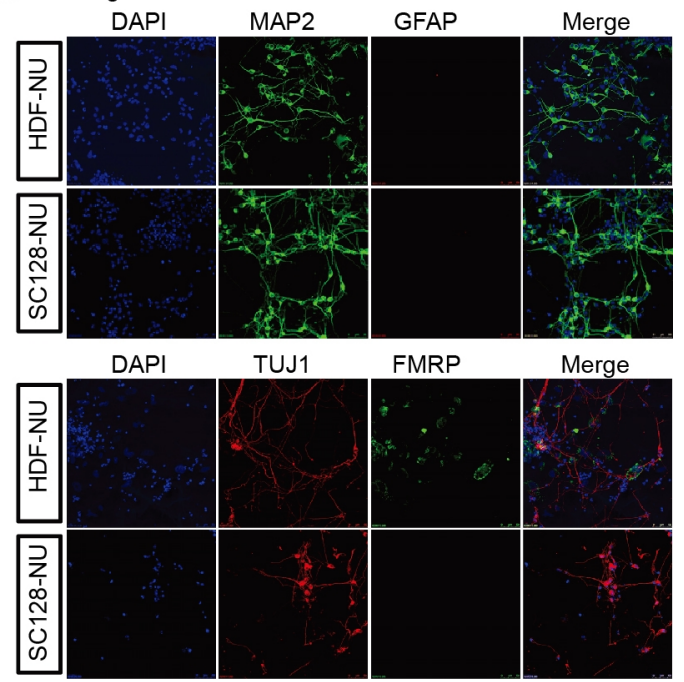

Figure 1 In-vitro differentiation of FXS-iPSC into neurons. A, The diagram of the neural differentiation process. B-D, Immunostaining of the cells using antibodies against FMRP, and pluripotent markers NANOG and SOX2 at iPSC stage (B); against neural epithelia cell markers NESTIN, SOX1, and PAX6 at NE stage (C), and against neuron markers MAP2 and TUJ1 at NU stage (D). iPSC, induced pluripotent cell; NE, neuroepithelia; NU, neuron.

We then performed a step-wise in-vitro differentiation of FXS-iPSC into neurons (Figure 1A). During the in-vitro differentiation process, we found that FXS-iPSC and its derived cells at different stages express the correct markers as does the control HDF2-iPSC, although FMRP expression was barely detected by fluorescence immunostaining (Figure 1B-D) and real-time RT-PCR (Figure S1C in Supporting Information). However, we noticed that neurons differentiated from FXS-iPSC are significantly fewer than those from HDF2-iPSC ( $73.2 \% \pm 0.8 \%$ vs. $83.7 \% \pm 3.9 \%, P=0.0019)$, which was consistent with the previous findings in FXS patient derived ESCs (Telias et al., 2013).

\section{FMRP deficiency results in altered gene expression pat- tern during neurogenesis}

To test our hypothesis weather the gene expression profile is changed by FMRP deficiency, we collected the RNA sam- ples at four developmental stages during in-vitro differentiation, i.e., 0-day (D0, iPSC stage), 6-day (D6, IA stage), 18-day (D18, NA stage) and 50-day (D50, neuron stage). We constructed the Tru-seq libraries following the manufacturer's protocol. After RNA-seq on the Illumina Hi-seq platform, we retrieved approximately 200 million mapped reads from the total 8 samples of FXS-iPSC and HDF2-iPSC. After performing unsupervised hierarchal clustering and principal component analysis (PCA), we found that FXS-iPSC and its derived cells share very similar gene expression patterns with HDF2-iPSC and its derived cells when given a certain stage respectively (Figure $2 \mathrm{~A}$ and $\mathrm{B}$ ). To validate our in-vitro differentiation method, we compared the transcriptomic profiles with the single-cell data at different stages by Pasca et al. (Pasca et al., 2011). We found that the expression patterns of our cell lines at early stages, i.e., D0 and D6, cluster closely with the other group's iPSC stage, whereas those at 
D18 and D50 match their neurosphere and neuron stages respectively (Figure 2C), which indicated that both HDF2-iPSC and FXS-iPSC were successfully differentiated into neurons. Taken together, FMRP deficiency results in subtle transcription perturbation, as regard to the affected genes and their mRNA level, and FXS-iPSC is capable of being differentiated into neurons morphologically similar to those derived from the control HDF2-iPSC.

We used the threshold of $P<0.05$ and $\log _{2}$ (fold change) $>1$ and found totally 1,559 differentially-expressed genes (DEGs) between FXS-iPSC and HDF2-iPSC by pairwise comparison during the whole neuron differentiation process (Figure 2D, Table S1 in Supporting Information). Most of the DEGs are at iPSC stage, and DEGs on D6 and D18 have
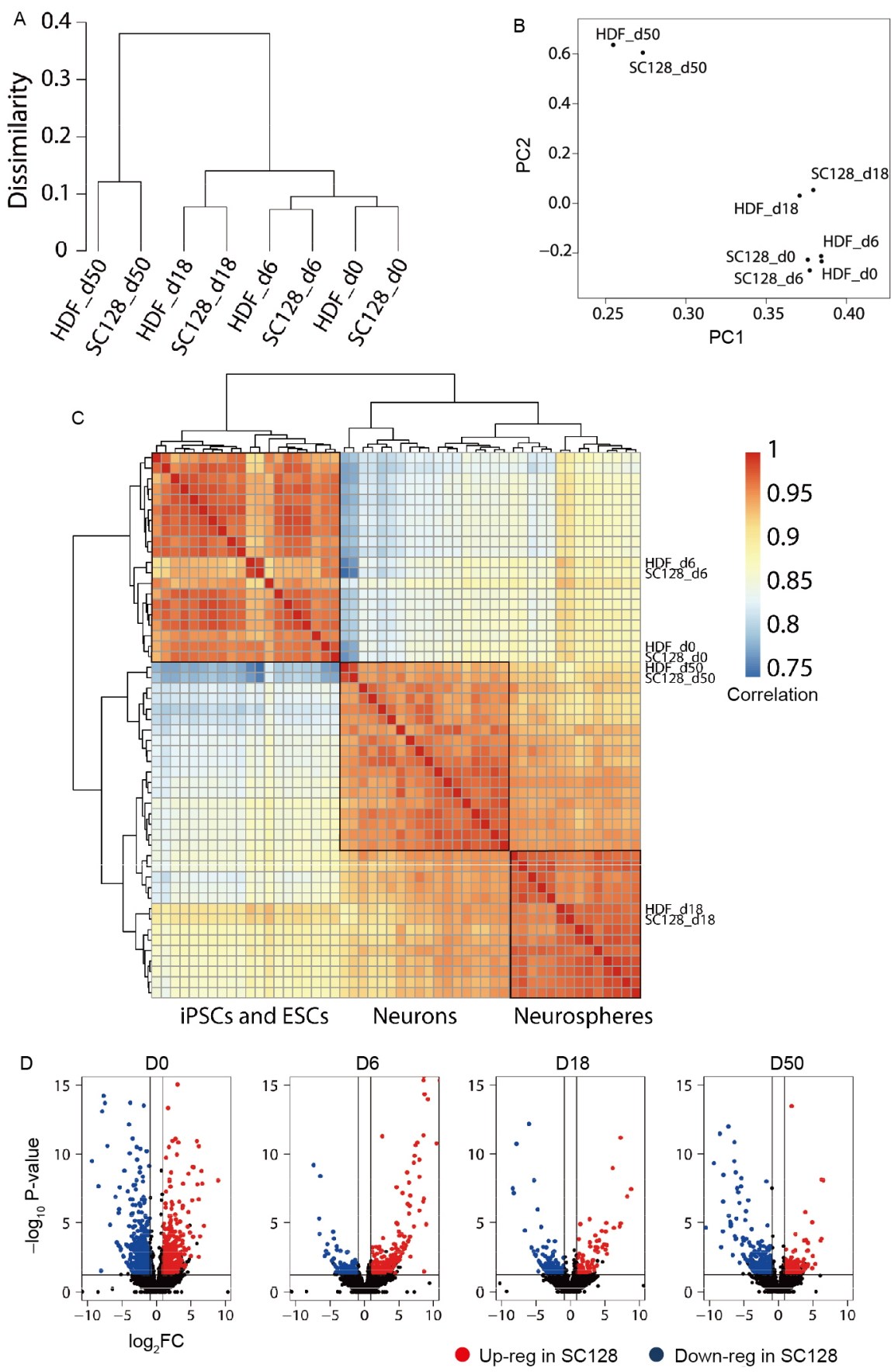

Figure 2 The gene expression pattern of FXS-iPSC during neurogenesis. A, Unsupervised hierarchical clustering of gene expression profiles well defines known phases of neurogenesis. B, Principal component analysis (PCA) of gene expression profiles at defined time points from both HDF and SC128 samples. C, Clustering of gene expression profile revealed similar patterns in neuronal differentiation as previously reported by Pasca et al. in 2011. D, Volcano plot shows an overall comparison of HDF and SC128 samples. $\log _{2}$ FC indicates $\log _{2}$ scaled fold change of gene expression in SC128 vs. HDF. 
a relatively high overlap with those on the other stages (Figure $\mathrm{S} 2$ in Supporting Information). Interestingly, GO analysis of the DEGs showed that up- and down-regulated genes in FXS-iPSC and its derived cells belong to different categories related to embryonic morphogenesis, neuronal differentiation and function, which underscores the fundamental defects in the transcriptional regulation during neuronal differentiation and will be further examined as follows.

\section{The gene expression profiles are consistent with those in the previous in-vitro differentiation of FXS-iPSC}

Due to the batch effect and genetic variation in different FXS patients, we next asked whether and how well the gene expression profiles from one FXS patient-derived cell line
(FXS-iPSC) and its control (HDF2-iPSC) can be generalized to explain the transcriptional alteration during neurogenesis in FXS patients. After literature search, we found a set of transcriptome data generated from FXS patient-derived iPS cells and their derived neurons (Halevy et al., 2015), which perfectly matched our work except that their data were generated by microarray and only collected at iPSC and neuron stages. In general, our data are in consistent with those from Halevy et al. (Halevy et al., 2015). As shown in Figure 3A and B, our RNA-seq data on D0 and D50 arerespectively clustered together with iPSCs and neurons in Halevy's data, but far away from WT and FXS fibroblasts, indicating that the quality of our in-vitro differentiation and RNA-seq is high. Since the data from Halevy et al. do not include inter-
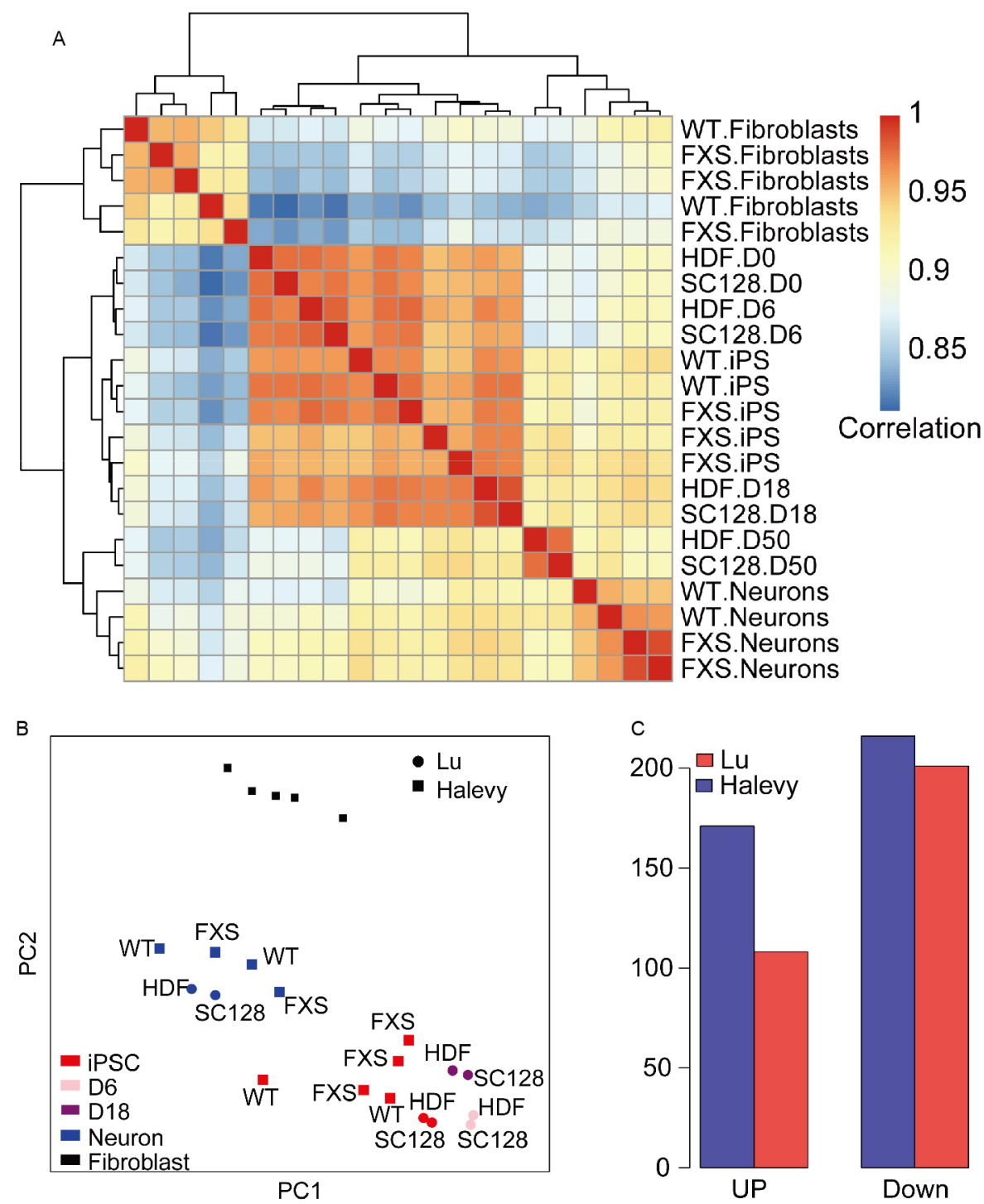

Figure 3 Integrated analysis of our RNA-seq data and those in the previous in-vitro differentiation of FXS-iPSCs. A, Heatmap shows hierarchical clustering of correlation between gene expression from our RNA-seq data and the microarray data (Halevy et al., 2015). Our samples are named HDF and SC128, whereas the samples from Halevy et al. are named WT and FXS. B, PCA of gene expression profiles shows the samples in the present work and the other group's work (Halevy et al., 2015) cluster at iPSC and neuron stages respectively. C, Number of DEGs at neuron stage found in our and Halevy's data. Up stands for genes up-regulated in FXS sample. Down stands for genes down-regulated in FXS sample. 
mediate stages during in-vitro differentiation, all our data on D0, D6 and D18 cluster with the iPSCs instead. We also noticed that our data cluster closely with each other, however those of Halevy et al. show more variation among different samples. Nevertheless, the data from both groups can detect a number of up-regulated and down-regulated DEGs at neuron stage (Figure 3C), which will be discussed in the following sections. In conclusion, our data are representative expression profiles during neurogenesis in FXS patients and can be further analyzed by combining other data from different platforms.

Distinctive gene expression patterns at neuron stage determine the phenotypic difference in neuronal differentiation between FXS-iPSC and HDF2-iPSC

We next investigated the altered gene expression patterns in FXS-iPSC at neuron stage. Heatmap of $\log _{2}$ fold change showed two distinct clusters of neuron-specific (D50) DEGs
(Figure 4A). Cluster 1 is composed of up-regulated genes (Figure 4A and B), while cluster 2 has all the down-regulated genes (Figure 4A and D). Interestingly, up- and down- regulated genes of FXS-iPSC at neuron stage are associated with functions including embryonic morphogenesis and synaptic transmission. As the final consequence of FMRP deficiency, the DEGs in this group may eventually reflect the perturbation of global transcription and thus lead to functional defects during neurogenesis. As shown in Table 1, we found some neurogenesis related genes in Cluster 1, e.g., WNT1, BMP4, $P O U 3 F 4, T F A P 2 C$ and $P A X 3$, suggesting that FXS-iPSC derived neurons are relatively immature. Interestingly, many genes in Cluster 2 encode potassium channels, e.g., KCNA1, $K C N C 3$, KCNG2, KCNIP4, KCNJ3, KCNK9, and KCNT1, whose down-regulation may cause neuronal defects in FXS patients. We validated the expression patterns of some genes by real-time RT-PCR (Figure 4A). Furthermore, the gene expression patterns in these two clusters are confirmed by com-
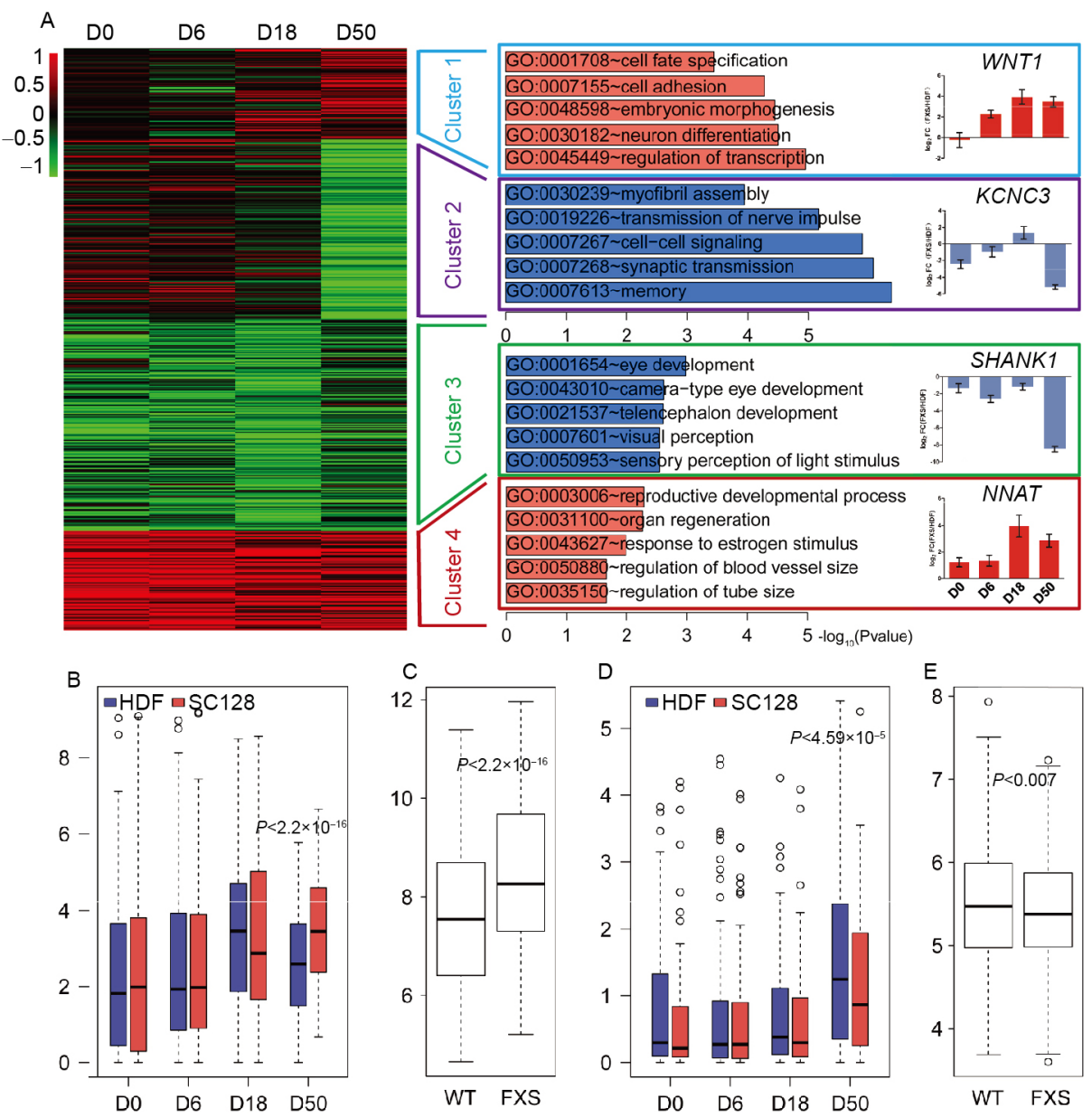

Figure 4 Four clusters of genes up- or down-regulated at neuron stage. A, Heatmap of $\log _{2}$ fold change (SC128/HDF) at different developmental stages reveals four clusters of genes either up- or down-regulated on D50. GO analysis indicated the biological functions of genes in each cluster. The mRNA level of representative genes in each cluster was validated by real-time RT-PCR. B, Boxplot shows up-regulation of genes in GO term "embryonic morphogenesis" (GO:0048598) in our RNA-seq data. C, The genes with the same GO term as in B (GO:0048598) are also up-regulated in Halevy's microarray data. D, Boxplot shows down-regulation of 79 potassium related genes (defined by HGNC) in our RNA-seq data. E, The same group of potassium related genes as in D is also down-regulated in Halevy's microarray data. The values of expression level were $\log _{2}$-transformed. $P$ values were calculated by paired $t$-test. 
parison of our data with those in the previous report by Halevy et al. (Halevy et al., 2015). For example, genes in GO term "embryonic morphogenesis" (GO:0048598) are significantly up-regulated (Figure 4B and C), and those encoding potassium channels are significantly down-regulated (Figure 4D and $\mathrm{E})$.

By contrast, there are also some genes in FXS-iPSC either down-regulated (Cluster 3) or up-regulated (Cluster 4) throughout the entire in-vitro neuronal differentiation, which execute important functions related to the development of nervous system (Figure 4A). We performed real-time RT-PCR (Figure 4A) and found that the temporal expression patterns of SHANK1 in Cluster 3 and NNAT in Cluster 4 are dramatically altered as referred to human brain transcriptome (HBT), which implied that these two genes are very likely related to intellectual disability of FXS. Finally, the biological network analysis (Figure 5A) further demonstrated that all these DEGs (Table 1) are in the central axes of neuronal functions and their combinatory regulation is essential for the mature neurons.

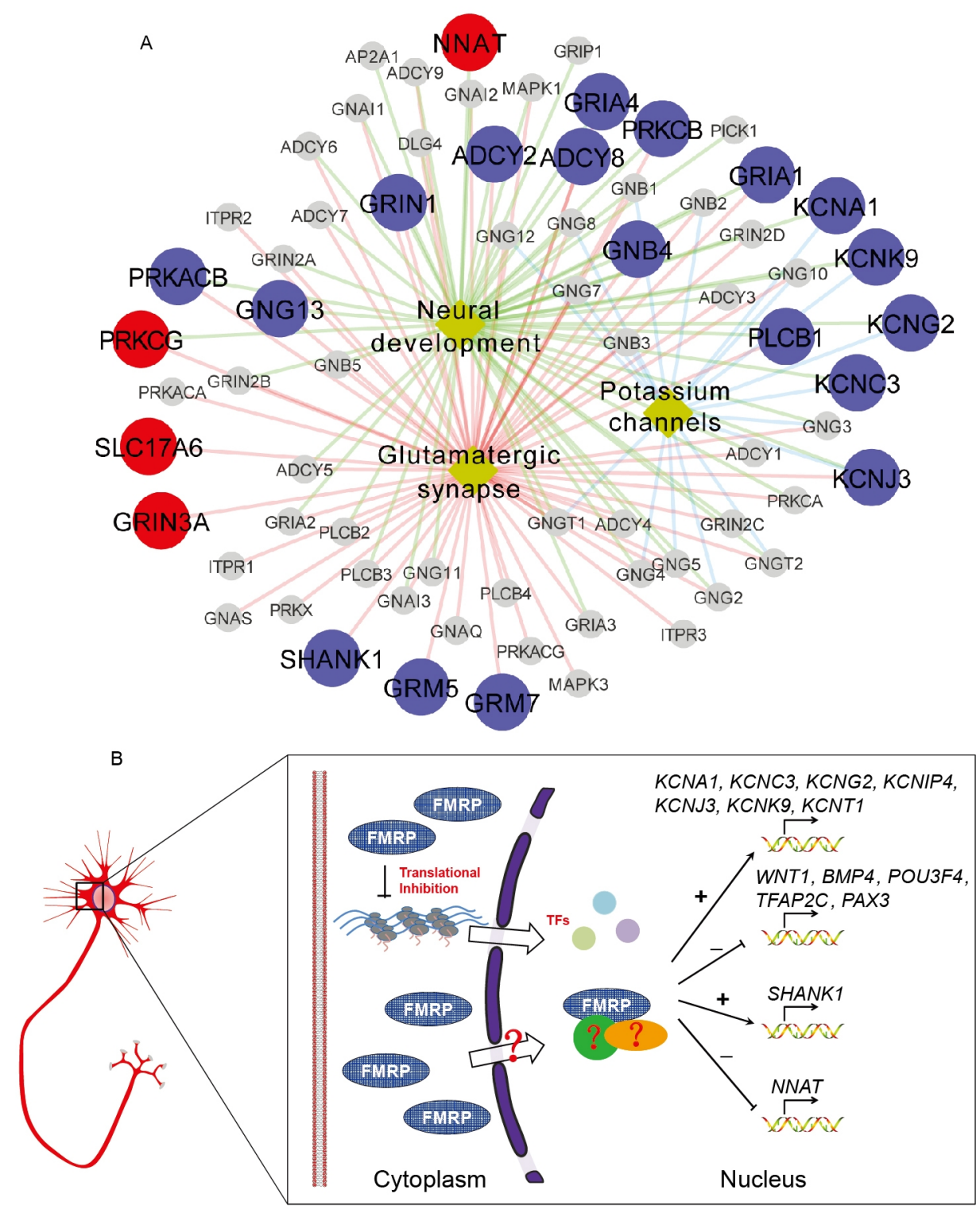

Figure 5 FMRP regulates the transcription of certain genes in the nucleus during neurogenesis. A, The biological function networks are diagramed using GeneMANIA, which show that the cooperation of DEGs is essential for neural development and function. The big circle highlight up- (red) and down- (blue) regulated DEGs found at the neuron stage (D50) in our work. The yellow diamonds in the center represent the major biological functions, i.e., neural development, potassium channels and glutamatergic synapse. The colored lines connect the biological function to each DEG respectively. B, The diagram shows that the transcription of different groups of genes during neuronal differentiation is positively (indicated by "+") or negatively (indicated by “-”) regulated by either the transcription factors whose translation is inhibited by FMRP, and/or nucleus-localized FMRP. However, it still needs to be elucidated how small amount of FMRP (5\%) is transported into nucleus (indicated by the question mark) and how it interacts with other unknown factors (indicated by the question mark) to regulate the transcription directly and/or indirectly. 
Table 1 Candidate genes misregulated in FXS-iPSC during in-vitro differentiation

\begin{tabular}{|c|c|c|c|c|}
\hline Symbol & Description & Location & Cluster & Function \\
\hline WNT1 & wingless-type MMTV integration site family member 1 & $12 \mathrm{q} 13$ & 3 & GO:0007399 nervous system development \\
\hline$B M P 4$ & bone morphogenetic protein 4 & $14 q 22-q 23$ & 3 & GO:0030154 cell differentiation \\
\hline TFAP2C & $\begin{array}{l}\text { transcription factor AP-2 gamma (activating enhancer } \\
\text { binding protein } 2 \text { gamma) }\end{array}$ & $20 \mathrm{q} 13.2$ & 3 & $\begin{array}{l}\text { GO:0006357 regulation of transcription from } \\
\text { RNA polymerase II promoter }\end{array}$ \\
\hline$K C N A 1$ & $\begin{array}{c}\text { potassium channel, voltage gated shaker related } \\
\text { subfamily A, member } 1\end{array}$ & $12 \mathrm{p} 13.32$ & 4 & GO:0006812 cation transport \\
\hline$K C N C 3$ & $\begin{array}{l}\text { potassium channel, voltage gated Shaw related } \\
\text { subfamily } \mathrm{C} \text {, member } 3\end{array}$ & $19 \mathrm{q} 13.33$ & 4 & GO:0006812cation transport \\
\hline$K C N G 2$ & $\begin{array}{l}\text { potassium channel, voltage gated modifier sub- } \\
\text { family } \mathrm{G} \text {, member } 2\end{array}$ & $18 \mathrm{q} 23$ & 4 & GO:0006812 cation transport \\
\hline KCNIP4 & Kv channel interacting protein 4 & $4 \mathrm{p} 15.32$ & 4 & GO:0007600 sensory perception \\
\hline$K C N K 9$ & potassium channel, two pore domain subfamily K, member 9 & $8 \mathrm{q} 24.3$ & 4 & GO:0006812 cation transport \\
\hline KCNT1 & potassium channel, sodium activated subfamily $\mathrm{T}$, member 1 & $9 \mathrm{q} 34.3$ & 4 & $\begin{array}{c}\text { GO:0008324 cation transmembrane } \\
\text { transporter activity }\end{array}$ \\
\hline SHANK1 & SH3 and multiple ankyrin repeat domains 1 & $19 q 13.3$ & 5 & $\begin{array}{c}\text { GO:2000463 positive regulation of excitatory } \\
\text { postsynaptic potential }\end{array}$ \\
\hline$N N A T$ & neuronatin & $20 \mathrm{q} 11.2-\mathrm{q} 12$ & 6 & GO:0007399 nervous system development \\
\hline
\end{tabular}

\section{DISCUSSION}

Investigators are pursuing the question of whether and how the transcription machinery is altered in the FXS patients (Bittel et al., 2007; D’Agata et al., 2002; Halevy et al., 2015), although the disturbed translation has been widely accepted as molecular mechanism underlying FXS (Darnell and Klann, 2013). The altered transcription can be explained by combinatory effects. First of all, RNA binding domains of FMRP help its recognition and translational suppression of approximate 6,000 mRNA targets (Ascano et al., 2012), 932 of which fall into the category of known transcription factors (TFs) (Vaquerizas et al., 2009). Thus the misregulated TFs indirectly cause the genome-wide transcription perturbation. Second, a small portion of FMRP resides inside nucleus, implying its nuclear functions such as transcriptional regulation, mRNA splicing and DNA damage repair. However, little is known on its involvement in transcriptional regulation except DNA damage repair (Alpatov et al., 2014). Lastly, the epigenetic changes on the 5' UTR of FMR1 promoter expand on the neighboring regions on $\mathrm{X}$ chromosome, which may affect the related gene expression patterns directly or indirectly. Unlike the previous low-throughput microarray data which examine the affected transcription in either Fmrl null mouse model (D'Agata et al., 2002) or lymphoblasts of male FXS patients (Bittel et al., 2007), we performed in-vitro differentiation of the patient derived iPS cells into neurons, comprehensively analyzed the expression profiling at each developmental stage, and discovered total 1,559 DEGs whose expression levels are altered due to FMRP deficiency. We categorized the DEGs in different patterned clusters (Table 1) and found that many of them crosstalk to each other and cooperate in major neuronal functions such as neural development, potassium channels and glutamatergic synapse (Figure 5A), which implied that their misregulation very likely leads to the pathophysiology of FXS. By combinatorial analysis of the data generated by us and other groups, we concluded that FMRP can regulate the transcription of certain groups of genes in the nucleus during neurogenesis (Figure 5B), however, the detailed mechanisms still need to be elucidated in the future.

The DEGs at neuron stage (Cluster 1 and Cluster 2) are mainly associated with neurogenesis, synaptic plasticity and circuit excitability, which implied that their misregulation at transcriptional level may contribute to the intellectual disorders in FXS patients. Some important TFs such as WNT1, BMP4, POU3F4, and TFAP2C are upregulated in FXS-iPSC derived neurons. As well known, WNT and BMP signaling is required to maintain the stem-cell status, and inhibition of BMP signaling pathway permits in-vitro neuronal differentiation. Mouse Pou3f4 is involved in a regulatory network for early neurogenesis activated by Pax6-BAF complex (Ninkovic et al., 2013). In zebrafish, spatiotemporal expression of Tfap $2 c$ together with Tfap $2 a$ is required for neural crest induction ( $\mathrm{Li}$ and Cornell, 2007). Thus the elevated expression of these TFs is most likely an indication of premature neurons, suggesting that the intrinsic transcriptional perturbation in FXS-iPSC prevents or postpones the neuronal differentiation processes. $P A X 3$ is also found in Cluster 1, which involves in neural crest induction, specification, and differenti- 
ation (Monsoro-Burq, 2015). So the high expression level of $P A X 3$ may break the balanced neuronal differentiation, e.g., increase or decrease neuron subtypes, resulting in the intellectual disorders of FXS. Cluster 2 includes many genes encoding potassium channels, i.e., $K C N A 1, K C N C 3, K C N G 2, K C$ NIP4, KCNJ3, KCNK9, and KCNT1, whose transcriptional level is lower in FXS-iPSC derived neurons. Different potassium channels play important roles in maintaining membrane potential in different neurons, whose misregulation are associated with intellectual disease such as FXS (Lee and Jan, 2012). To date, FMRP is found to modulate the function of four potassium channels, encoded by KCNT1 (Brown et al., 2010), KCNC1 (Strumbos et al., 2010) and KCND2 (Lee et al., 2011) and KCNMA1 (Deng et al., 2013) respectively, by either translational regulation or direct protein-protein interaction. In line with this, our finding of down-regulated expression of potassium channels revealed another layer of transcriptional regulation by FMRP in controlling membrane potential related to pathology of FXS. We found a few up-regulated (PRKCG and GRIN3A in Cluster 1) or down-regulated (GRIN1, GRIA4, GRIN2B, GRM5 and GRM7 in Cluster 2) DEGs in mGluR pathway. Although there is no particular pattern that fits into the translational regulation in the mGluR theory, we speculated that the down-regulated expression of mGluR5 itself may be a feedback due to translational misregulation by FMRP deficiency.

The spatiotemporal transcription is precisely regulated during neuronal development, supported by the database in HBT (Johnson et al., 2009; Kang et al., 2011; Pletikos et al., 2014). When we examined the clusters of genes either up- or downregulated throughout all the stages (Figure 4A), we found that the temporal transcription patterns are dramatically inversed compared with those in HBT. For example, we found two candidates $\mathrm{SH} 3$ and multiple ankyrin repeat domains 1 (SHANK1) and neuronatin (NNAT), whose misregulation are very likely related to FXS (Figure 4A). As diagrammed in HBT, SHANK1 expression increases and reaches the plateau after birth. But in the FXS-iPSC derived neurons, SHANK1 mRNA level is kept low and then steeply decreased at D50. SHANK1 encodes a synaptic scaffold protein and its mutations have a strong correlation with autism spectrum disorders (ASD) in both patients (Sato et al., 2012; Leblond et al., 2014) and animal models (Hung et al., 2008). Although a previous report did not find significant change of SHANK1 mRNA level in $\mathrm{Fmrl}^{-/-}$mice (Schutt et al., 2009), we argue that this was probably due to the variation in model system and sample preparation. The function of SHANK1 in FXS pathology should be further validated as there have been many evidences of the phenotypic overlap between ASD and FXS (Devitt et al., 2015). Compared to HBT results which show that NNAT expression declines during neuronal development and reaches the bottom after birth, NNAT mRNA level in FXS-iPSC derived neurons is modestly high and spikes at
D18 and D50. NNAT, an imprinted gene expressed from paternal allele, is down-regulated when PC12 cells undergo neuronal differentiation (Joseph et al., 1996; Zheng et al., 2002). Since high level of NNAT aggregates are found in Lafora disease (Sharma et al., 2011; Sharma et al., 2013) and phenylketonuria (Surendran et al., 2005), our data suggested that elevated NNAT expression may hinder the neuronal development in FXS patients.

Our results agreed on the widely-accepted fact that FXS is caused, at least initiated, by FMR1 single gene mutation (Bagni et al., 2012; Nelson et al., 2013). Otherwise, if DNA methylation at the $5^{\prime}$ UTR of FMRI and the subsequent epigenetic alteration expanded and repressed the adjacent gene expression, we should have discovered the repression of certain genes near fragile site on $\mathrm{X}$ chromosome throughout the entire neuronal differentiation. We did find the clusters of genes which are either up-regulated or down-regulated through iPSC to neuron stage (Figure 4A, Figure S2A and B in Supporting Information). However, GO analysis showed that both up- and down- regulated genes had rather low enrichment for certain biological processes (Figure 4A). We found 9 down-regulated genes at all stages, none of which were on X chromosome (Figure S2C in Supporting Information). Instead, most of them are near the telomeres of chromosome 19, including 19p-specific zinc finger genes (Figure S2C in Supporting Information) (Mohrenweiser et al., 1998), i.e., ZFN558, ZFN681. Since males have higher crossover ratio near the telomeres of chromosome 19 (Mohrenweiser et al., 1998; Tapper et al., 2005), the decreased expression of these genes is most likely the stochastic alteration due to sex-specific recombination. Together, FMR1 mutation does not directly give rise to transcriptional repression near its locus on $\mathrm{X}$ chromosome.

In conclusion, we discovered the transcriptional perturbation during neuronal differentiation by intensive analysis of high-throughput RNA-seq results using in-vitro iPS cell model. We found many candidate genes which are very likely related to intellectual disability in FXS patients. Since most of the genes have not yet been reported in FXS patients or disease models, our work provided a rich resource for both academic study on the molecular etiology of FXS and pharmaceutical screening for new medicine of the cure.

\section{MATERIALS AND METHODS}

\section{Animals}

Pregnant CF1 mice were purchased from Slac Laboratory Animal (Shanghai) and raised in the animal facility at Tongji University. All animal experiments were approved by Tongji University's Committee on Animal Care and Use (\# TJMED013-063). The mice in static cages were kept in a 12-h light, 12-h dark cycle with ad libitum access to food and water. We made all efforts to reduce animal suffering. To make mouse 
embryonic fibroblast (MEF), we sacrificed the pregnant mice by cervical dislocation within a short period of about $15 \mathrm{~s}$.

\section{Cell culture}

We obtained HDF2-iPSC cell line from UCLA Stem Cell Core (Liao et al., 2010) and FXS-iPSC cell line (named SC128) from Dr. Philip H. Schwartz at Children's Hospital of Orange County, USA (Brick et al., 2014). Cells were maintained at $37^{\circ} \mathrm{C}$ and $5 \% \mathrm{CO}_{2}$, and the media changed every three days. For mouse embryonic fibroblast (MEF) isolation, uteri were isolated from 13.5-day-pregnant $\mathrm{CF} 1$ mice and washed with phosphate-buffered saline (PBS). The fetal head and visceral tissues were removed, and the remaining bodies washed with fresh PBS, transferred into a $0.1 \mathrm{mmol} \mathrm{L}^{-1} \operatorname{trypsin} / 1 \mathrm{mmol} \mathrm{L}^{-1}$ ethylene diamine tetraacetic acid (EDTA) solution, and incubated for $20 \mathrm{~min}$. After incubation, MEF culture medium (dulbecco's modified eagle medium (DMEM) containing 15\% defined FBS) was added and pipetted up and down to dissociate cells. MEFs were used as feeders at passages one to three.

iPS cells were maintained in DMEM/F12 (Invitrogen, USA), supplemented with $2 \mathrm{mmol} \mathrm{L}^{-1} \mathrm{~L}$-glutamine (Invitrogen), $1 \mathrm{mmol} \mathrm{L}^{-1} \beta$-mercaptoethanol, $1 \times$ non-essential amino acids (NEAA, Invitrogen), 20\% knock-out serum replacement (KSR, Invitrogen), $100 \mathrm{U} \mathrm{mL}^{-1}$ penicillin and $100 \mu \mathrm{g} \mathrm{mL}^{-1}$ streptomycin (Invitrogen). hiPS cells were maintained on MEF cells. For picking and passaging, hiPS cells were washed once with ES media 3, incubated with $0.1 \%$ collagenase type IV solution (StemCell Tech, USA) for $10 \mathrm{~min}$, and then mechanically disrupted. An appropriate volume of medium was added and hiPS cells were transferred onto MEF feeder cells on a new dish. The cultures were split at a 1:1 ratio until passage 3 , and 1:4 thereafter.

\section{In-vitro neural differentiation}

We performed the in-vitro neural differentiation following a previous described protocol (Zhang and Zhang, 2010). iPS colonies were enzymatically lifted (CollagenaseIV, $1 \mathrm{mg} \mathrm{mL}^{-1}$ ) and grown in suspension to create floating iPS cell aggregates (IA). IA were grown for 6 days: 4 days in DMEM:F12 (Invitrogen) containing 20\% KSR (Invitrogen), $1 \%$ Glutamax (Invitrogen), 1\% NEAA (Invitrogen); and 2 days in neural induction medium (NIM) composed of DMEM:F12 (Invitrogen) containing 1\% N2 (Invitrogen), $1 \%$ Glutamax (Invitrogen), 1\% NEAA (Invitrogen) and heparin ( $1 \mathrm{mg} \mathrm{mL}^{-1}$, Sigma, USA); IA were reseeded onto laminin $\left(20 \mu \mathrm{g} \mathrm{mL}^{-1}\right.$, Gibco) coated 6-well plate and cultured in NIM for 11 days, until they developed into the definitive neural epithelia (NE) containing neural tube-like rosettes. NE were detached by gentle pipetting leaving the peripheral flat cells attached and further grown in suspension medium (NIM supplemented with 1\% B27 to create neural epithelia aggregates (NA) for 8 days. At day 25, NA were mechanically digested by accutase/trypsin (1:1) and plated on glass coverslips (Fisher Scientific, USA) coated with poly-L-ornithine/laminin (Sigma, at a final concentration of 10 and $20 \mu \mathrm{g} \mathrm{mL}^{-1}$, respectively). Plated cells were grown in neural differentiation medium (NDM) composed of neurobasal medium (Invitrogen) supplemented with 1\% N2 (Invitrogen), 1\% B27 (without Vitamin A, Invitrogen), 1\% Glutamax (Invitrogen), 1\% NEAA (Invitrogen), plus BDNF, GDNF and IGF-1 (Peprotech, all at a final concentration of $10 \mathrm{ng} \mathrm{mL}^{-1}$ ). Following NS final plating, postmitotic neurons were developed within 10 days. Fully developed neurons were observed 25 days post-plating.

\section{RNA extraction and real-time RT-PCR}

Cell samples of HDF2-iPSC and SC128 were collected at four stages during the neuronal differentiation, i.e., iPSC (D0), IA (D6), NE (D18), and mature neuron (D50). RNA was extracted with TRIzol Reagent (Ambion, USA) according to the manufacturer's protocol. The first strand cDNA was synthesized using 200 ng of RNA with Revert Aid First Strand cDNA Synthesis Kit (Thermo, USA). Real-time reverse transcription PCR (RT-PCR) was performed using ABI Stepone Plus to detect the fluorescence of SYBR Green (TIAGEN, Beijing). GAPDH was used as internal control for $\Delta \Delta C_{\mathrm{t}}$ analysis. The primers are listed in Table S2 in Supporting Information.

\section{Immunohistochemistry}

Cells on coverslips were fixed in $4 \%$ paraformaldehyde in PBS (HyClone, USA) and immunostained according to the standard protocols. Samples were washed three times in PBS before they were permeablized and blocked in PBS (HyClone) with 5\% normal goat serum (Yeasen, Shanghai, $4 \%$ BSA was used for goat polyclonal antibody), $0.3 \%$ Triton $\mathrm{X}$ for $1 \mathrm{~h}$ at room temperature. They were incubated with diluted primary antibodies overnight at $4{ }^{\circ} \mathrm{C}$ : SOX2 (1:100, mouse monoclonal, Santa Cruz Biotechnology, USA), NANOG (1:1,000, goat polyclonal, R\&D Systems, USA), SOX1 (1:100, goat polyclonal, R\&D Systems), FMRP (1:1,000, rabbit polyclonal, Abcam, UK), NESTIN (1:250, mouse monoclonal, BD bioscience, USA), PAX6 (1:200, mouse monoclonal, DSHB, USA), GFAP (1:500, mouse monoclonal, Novus Biologicals, USA), MAP2 $(1: 1,000$, rabbit polyclonal, Chemicon, USA), and TUJ1 $(1: 1,000$, mouse monoclonal, Covance, USA). After three-time washes in PBS (HyClone), they were incubated with appropriate flurochrome-conjugated secondary antibodies (Cy2-conjugated 1:300, or Cy3-conjugated, 1:500; both from Jackson Immunoresearch, West Grove, PA) for $2 \mathrm{~h}$ at room temperature. Cells were mounted using Vectashield containing 4',6-diamidino-2-phenylindole (DAPI; Vector Lab, USA) and analyzed by luorescent microscope (Nikon eclipse Ti-S, Japan and Leica TCS SPS, Germany). 


\section{Library construction and RNA-seq}

We constructed RNA-seq libraries following the protocol described in Illumina TruSeq ${ }^{\mathrm{TM}}$ RNA Sample Preparation Guide. Briefly, we started with $400 \mathrm{ng}$ of total RNA. We then purified poly-A containing mRNA molecules by poly-T oligo-attached magnetic beads. After RT and complementary cDNA strand synthesis, we did end-repair and adapter ligation. Finally we amplified the cDNA by 15 -cycle PCR. The concentration of the amplified product was determined by Qubit Fluorometer (Invitrogen). Ten nmol of each sample was sequenced according to the manufacturer's instruction with Illumin Hiseq 2000. Sequencing reads were mapped to the hg19 genome using burrows-wheeler alignment tool Tophat (Bowtie2).

\section{Bioinformatics analysis}

The raw reads were cleaned by removing adapter sequences, reads containing poly-N and low-quality sequences $(Q<20)$. Clean reads were aligned to the reference genome (hg19) using TopHat v2.0.13 (Kim et al., 2013) with default parameters, allowing no more than two mismatches. The statistics of raw reads, mapped reads were summarized in Table S3 in Supporting Information. For each transcript, fragment per kilobase per million (RPKM) mapped reads were calculated to evaluate the expression level. The differentially expressed genes were identified by the tool Cuffdiff v1.3.0 (Trapnell et al., 2012). A $P$-value of 0.05 and a $\log _{2}$ (fold-change) of 1 were set as the threshold for significant differential expression. Unsupervised clustering ( $k$-means, $k=7$ ) was applied to the $\log _{2}$ scaled fold change of SC128 vs. HDF. Gene ontology (GO) enrichment analysis of differentially expressed genes (DEGs) was performed by DAVID online tool (http://david.abcc.ncifcrf.gov) (Huang da et al., 2009). GO terms with $P$-value smaller than 0.01 were selected to present. Up- and down-regulated DEGs at neuron stage were selected to generate the biological function networks by cytoscape application GeneMANIA (Warde-Farley et al., 2010). The microarray data used for integrated analysis were retrieved from the Gene Expression Omnibus (GEO) (http://www.ncbi.nlm.nih.gov/geo/) with access number GSE25542 (Pasca et al., 2011) and GSE62721 (Halevy et al., 2015). RMA was performed to normalize probe signal. The DEGs shared by both our data and the microarray data were chosen for downstream analysis. Gene expression level in between different samples and datasets was normalized by "combat" function in Bioconductor SVA package to remove batch effects. $P$-value of 0.01 and a $\log _{2}$ (fold-change) of 1 were set as the threshold for calling DEGs in the microarray data.

Compliance and ethics The author(s) declare that they have no conflict of interest.

Acknowledgements We thank Dr. Philip H. Schwartz, Children's Hos- pital of Orange County, for the kind gift of SC128 cell line. This work was supported by National Program on Key Basic Research Project (2015CB964601, 2015CB964702), Joint Research Fund for Overseas Chinese, Hong Kong and Macao Young Scholars (31428016), National Natural Science Foundation of China (Key Program 81430026), Scientific Research Foundation for the Returned Overseas Chinese Scholars, State Education Ministry (Xianmin Zhu), Shanghai Municipal Commission of Health and Family Planning (XBR2013094), and Jiangsu Science and Technology Planning Project (BM2014052).

Alpatov, R., Lesch, B.J., Nakamoto-Kinoshita, M., Blanco, A., Chen, S., Stützer, A., Armache, K.J., Simon, M.D., Xu, C., Ali, M., Murn, J., Prisic, S., Kutateladze, T.G., Vakoc, C.R., Min, J., Kingston, R.E., Fischle, W., Warren, S.T., Page, D.C., and Shi, Y. (2014). A chromatin-dependent role of the fragile $\mathrm{X}$ mental retardation protein FMRP in the DNA damage response. Cell 157, 869-881.

Ascano, M., Mukherjee, N., Bandaru, P., Miller, J.B., Nusbaum, J.D., Corcoran, D.L., Langlois, C., Munschauer, M., Dewell, S., Hafner, M., Williams, Z., Ohler, U., and Tuschl, T. (2012). FMRP targets distinct mRNA sequence elements to regulate protein expression. Nature 492, 382-386.

Auerbach, B.D., Osterweil, E.K., and Bear, M.F. (2011). Mutations causing syndromic autism define an axis of synaptic pathophysiology. Nature 480, 63-68.

Bagni, C., Tassone, F., Neri, G., and Hagerman, R. (2012). Fragile X syndrome: causes, diagnosis, mechanisms, and therapeutics. J Clin Invest 122, 4314-4322.

Bear, M.F., Huber, K.M., and Warren, S.T. (2004). The mGluR theory of fragile X mental retardation. Trends Neurosci 27, 370-377.

Bittel, D.C., Kibiryeva, N., and Butler, M.G. (2007). Whole genome microarray analysis of gene expression in subjects with fragile $\mathrm{X}$ syndrome. Genet Med 9, 464-472.

Brick, D.J., Nethercott, H.E., Montesano, S., Banuelos, M.G., Stover, A.E., Schutte, S.S., O’Dowd, D.K., Hagerman, R.J., Ono, M., Hessl, D.R., Tassone, F., and Schwartz, P.H. (2014). The autism spectrum disorders stem cell resource at children's hospital of orange county: implications for disease modeling and drug discovery. Stem Cells Transl Med 3, 1275-1286.

Brown, M.R., Kronengold, J., Gazula, V.R., Chen, Y., Strumbos, J.G., Sigworth, F.J., Navaratnam, D., and Kaczmarek, L.K. (2010). Fragile $\mathrm{X}$ mental retardation protein controls gating of the sodium-activated potassium channel Slack. Nat Neurosci 13, 819-821.

Cruz-Martin, A., Crespo, M., and Portera-Cailliau, C. (2010). Delayed stabilization of dendritic spines in fragile X mice. J Neurosci 30, 7793-7803.

D'Agata, V., Warren, S.T., Zhao, W., Torre, E.R., Alkon, D.L., and Cavallaro, S. (2002). Gene expression profiles in a transgenic animal model of fragile X syndrome. Neurobiol Dis 10, 211-218.

D'Hulst, C., and Kooy, R.F. (2007). The GABAA receptor: a novel target for treatment of fragile X? Trends Neurosci 30, 425-431.

Darnell, J.C., and Klann, E. (2013). The translation of translational control by FMRP: therapeutic targets for FXS. Nat Neurosci 16, 1530-1536.

Darnell, J.C., Van Driesche, S.J., Zhang, C., Hung, K.Y.S., Mele, A., Fraser, C.E., Stone, E.F., Chen, C., Fak, J.J., Chi, S.W., Licatalosi, D.D., Richter, J.D., and Darnell, R.B. (2011). FMRP stalls ribosomal translocation on mRNAs linked to synaptic function and autism. Cell 146, 247-261.

Deng, P.Y., Rotman, Z., Blundon, J.A., Cho, Y., Cui, J., Cavalli, V., Zakharenko, S.S., and Klyachko, V.A. (2013). FMRP regulates neurotransmitter release and synaptic information transmission by modulating action potential duration via BK channels. Neuron 77, 696-711.

Devitt, N., Gallagher, L., and Reilly, R. (2015). Autism Spectrum Disorder (ASD) and Fragile X Syndrome (FXS): two overlapping disorders reviewed through electroencephalography-what can be interpreted from the available information? Brain Scis 5, 92-117.

Devys, D., Lutz, Y., Rouyer, N., Bellocq, J.P., and Mandel, J.L. (1993). The FMR-1 protein is cytoplasmic, most abundant in neurons and appears 
normal in carriers of a fragile X premutation. Nat Genet 4, 335-340.

Dolen, G., Osterweil, E., Rao, B.S., Smith, G.B., Auerbach, B.D., Chattarji, S., and Bear, M.F. (2007). Correction of fragile X syndrome in mice. Neuron 56, 955-962.

Eberhart, D.E., Malter, H.E., Feng, Y., and Warren, S.T. (1996). The fragile $\mathrm{X}$ mental retardation protein is a ribonucleoprotein containing both nuclear localization and nuclear export signals. Hum Mol Genet 5, 1083-1091.

Eiges, R., Urbach, A., Malcov, M., Frumkin, T., Schwartz, T., Amit, A., Yaron, Y., Eden, A., Yanuka, O., Benvenisty, N., and Ben-Yosef, D. (2007). Developmental study of fragile X syndrome using human embryonic stem cells derived from preimplantation genetically diagnosed embryos. Cell Stem Cell 1, 568-577.

Feng, Y., Gutekunst, C.A., Eberhart, D.E., Yi, H., Warren, S.T., and Hersch, S.M. (1997). Fragile X mental retardation protein: nucleocytoplasmic shuttling and association with somatodendritic ribosomes. J Neurosci 17, 1539-1547.

Goebel-Goody, S.M., Wilson-Wallis, E.D., Royston, S., Tagliatela, S.M., Naegele, J.R., and Lombroso, P.J. (2012). Genetic manipulation of STEP reverses behavioral abnormalities in a fragile $\mathrm{X}$ syndrome mouse model. Genes Brain Behav 11, 586-600.

Halevy, T., Czech, C., and Benvenisty, N. (2015). Molecular mechanisms regulating the defects in fragile $\mathrm{X}$ syndrome neurons derived from human pluripotent stem cells. Stem Cell Rep 4, 37-46.

Hayashi, M.L., Shankaranarayana Rao, B.S., Seo, J.S., Choi, H.S., Dolan, B.M., Choi, S.Y., Chattarji, S., and Tonegawa, S. (2007). Inhibition of p21-activated kinase rescues symptoms of fragile $\mathrm{X}$ syndrome in mice. Proc Natl Acad Sci USA 104, 11489-11494.

Huang da, W., Sherman, B.T., and Lempicki, R.A. (2009). Systematic and integrative analysis of large gene lists using DAVID bioinformatics resources. Nat Protoc 4, 44-57.

Huang, S., and Fu, X.B. (2014). Stem cell therapies and regenerative medicine in China. Sci China Life Sci 57, 157-161.

Hung, A.Y., Futai, K., Sala, C., Valtschanoff, J.G., Ryu, J., Woodworth, M.A., Kidd, F.L., Sung, C.C., Miyakawa, T., Bear, M.F., Weinberg, R.J., and Sheng, M. (2008). Smaller dendritic spines, weaker synaptic transmission, but enhanced spatial learning in mice lacking Shank1. J Neurosci 28, 1697-1708.

Johnson, M.B., Kawasawa, Y.I., Mason, C.E., Krsnik, , Coppola, G., Bogdanović, D., Geschwind, D.H., Mane, S.M., State, M.W., and Šestan, N. (2009). Functional and evolutionary insights into human brain development through global transcriptome analysis. Neuron 62, 494-509.

Joseph, R., Tsang, W., Dou, D., Nelson, K., and Edvardsen, K. (1996). Neuronatin mRNA in PC12 cells: downregulation by nerve growth factor. Brain Res 738, 32-38.

Kang, H.J., Kawasawa, Y.I., Cheng, F., Zhu, Y., Xu, X., Li, M., Sousa, A.M.M., Pletikos, M., Meyer, K.A., Sedmak, G., Guennel, T., Shin, Y., Johnson, M.B., Krsnik, Z., Mayer, S., Fertuzinhos, S., Umlauf, S., Lisgo, S.N., Vortmeyer, A., Weinberger, D.R., Mane, S., Hyde, T.M., Huttner, A., Reimers, M., Kleinman, J.E., and Sestan, N. (2011). Spatio-temporal transcriptome of the human brain. Nature 478, 483-489.

Kao, D.I., Aldridge, G.M., Weiler, I.J., and Greenough, W.T. (2010). Altered mRNA transport, docking, and protein translation in neurons lacking fragile X mental retardation protein. Proc Natl Acad Sci USA 107, 15601-15606.

Kim, D., Pertea, G., Trapnell, C., Pimentel, H., Kelley, R., and Salzberg, S.L. (2013). TopHat2: accurate alignment of transcriptomes in the presence of insertions, deletions and gene fusions. Genome Biol 14, R36.

Laggerbauer, B., Ostareck, D., Keidel, E.M., Ostareck-Lederer, A., and Fischer, U. (2001). Evidence that fragile X mental retardation protein is a negative regulator of translation. Hum Mol Genet 10, 329-338.

Leblond, C.S., Nava, C., Polge, A., Gauthier, J., Huguet, G., Lumbroso, S., Giuliano, F., Stordeur, C., Depienne, C., Mouzat, K., Pinto, D., Howe, J., Lemière, N., Durand, C.M., Guibert, J., Ey, E., Toro, R., Peyre, H., Mathieu, A., Amsellem, F., Rastam, M., Gillberg, I.C., Rappold, G.A.,
Holt, R., Monaco, A.P., Maestrini, E., Galan, P., Heron, D., Jacquette, A., Afenjar, A., Rastetter, A., Brice, A., Devillard, F., Assouline, B., Laffargue, F., Lespinasse, J., Chiesa, J., Rivier, F., Bonneau, D., Regnault, B., Zelenika, D., Delepine, M., Lathrop, M., Sanlaville, D., Schluth-Bolard, C., Edery, P., Perrin, L., Tabet, A.C., Schmeisser, M.J., Boeckers, T.M., Coleman, M., Sato, D., Szatmari, P., Scherer, S.W., Rouleau, G.A., Betancur, C., Leboyer, M., Gillberg, C., Delorme, R., Bourgeron, T., and Barsh, G.S. (2014). Meta-analysis of SHANK mutations in autism spectrum disorders: a gradient of severity in cognitive impairments. PLoS Genet 10, e1004580.

Lee, H.Y., Ge, W.P., Huang, W., He, Y., Wang, G.X., Rowson-Baldwin, A., Smith, S.J., Jan, Y.N., and Jan, L.Y. (2011). Bidirectional regulation of dendritic voltage-gated potassium channels by the fragile $\mathrm{X}$ mental retardation protein. Neuron 72, 630-642.

Lee, H.Y., and Jan, L.Y. (2012). Fragile X syndrome: mechanistic insights and therapeutic avenues regarding the role of potassium channels. Curr Opin Neurobiol 22, 887-894.

Li, W., and Cornell, R.A. (2007). Redundant activities of Tfap2a and Tfap2c are required for neural crest induction and development of other non-neural ectoderm derivatives in zebrafish embryos. Dev Biol 304, 338-354.

Liao, J.L., Yu, J., Huang, K., Hu, J., Diemer, T., Ma, Z., Dvash, T., Yang, X.J., Travis, G.H., Williams, D.S., Bok, D., and Fan, G. (2010). Molecular signature of primary retinal pigment epithelium and stem-cell-derived RPE cells. Human Mol Genets 19, 4229-4238.

Lindemann, L., Jaeschke, G., Michalon, A., Vieira, E., Honer, M., Spooren, W., Porter, R., Hartung, T., Kolczewski, S., Buttelmann, B., Flament, C., Diener, C., Fischer, C., Gatti, S., Prinssen, E.P., Parrott, N., Hoffmann, G., and Wettstein, J.G. (2011). CTEP: a novel, potent, long-acting, and orally bioavailable metabotropic glutamate receptor 5 inhibitor. J Pharmacol Exp Ther 339, 474-486.

Lu, R., Wang, H., Liang, Z., Ku, L., O’Donnell, W.T., Li, W., Warren, S.T., and Feng, Y. (2004). The fragile X protein controls microtubule-associated protein $1 \mathrm{~B}$ translation and microtubule stability in brain neuron development. Proc Natl Acad Sci USA 101, 15201-15206.

Michalon, A., Sidorov, M., Ballard, T.M., Ozmen, L., Spooren, W., Wettstein, J.G., Jaeschke, G., Bear, M.F., and Lindemann, L. (2012). Chronic pharmacological mGlu5 inhibition corrects fragile $\mathrm{X}$ in adult mice. Neuron 74, 49-56.

Mohrenweiser, H.W., Tsujimoto, S., Gordon, L., and Olsen, A.S. (1998). Regions of sex-specific hypo- and hyper-recombination identified through integration of 180 genetic markers into the metric physical map of human chromosome 19. Genomics 47, 153-162.

Monsoro-Burq, A.H. (2015). PAX transcription factors in neural crest development. Semin Cell Dev Biol 44, 87-96.

Muddashetty, R.S., Kelic, S., Gross, C., Xu, M., and Bassell, G.J. (2007). Dysregulated metabotropic glutamate receptor-dependent translation of AMPA receptor and postsynaptic density-95 mRNAs at synapses in a mouse model of fragile X syndrome. J Neurosci 27, 5338-5348.

Nelson, D.L., Orr, H.T., and Warren, S.T. (2013). The unstable repeats - three evolving faces of neurological disease. Neuron 77, $825-843$.

Ninkovic, J., Steiner-Mezzadri, A., Jawerka, M., Akinci, U., Masserdotti, G., Petricca, S., Fischer, J., von Holst, A., Beckers, J., Lie, C.D., Petrik, D., Miller, E., Tang, J., Wu, J., Lefebvre, V., Demmers, J., Eisch, A., Metzger, D., Crabtree, G., Irmler, M., Poot, R., and Götz, M. (2013). The BAF complex interacts with Pax6 in adult neural progenitors to establish a neurogenic cross-regulatory transcriptional network. Cell Stem Cell 13, 403-418.

Osterweil, E.K., Krueger, D.D., Reinhold, K., and Bear, M.F. (2010). Hypersensitivity to mGluR5 and ERK1/2 leads to excessive protein synthesis in the hippocampus of a mouse model of fragile X syndrome. J Neurosci 30, 15616-15627.

Pan, F., Aldridge, G.M., Greenough, W.T., and Gan, W.B. (2010). Dendritic spine instability and insensitivity to modulation by sensory experience in a mouse model of fragile X syndrome. Proc Natl Acad Sci USA 107, 17768-17773. 
Pasca, S.P., Portmann, T., Voineagu, I., Yazawa, M., Shcheglovitov, A., Pasca, A.M., Cord, B., Palmer, T.D., Chikahisa, S., Nishino, S., Bernstein, J.A., Hallmayer, J., Geschwind, D.H., and Dolmetsch, R.E. (2011). Using iPSC-derived neurons to uncover cellular phenotypes associated with Timothy syndrome. Nat Med 17, 1657-1662.

Pfeiffer, B.E., and Huber, K.M. (2007). Fragile X mental retardation protein induces synapse loss through acute postsynaptic translational regulation. J Neurosci 27, 3120-3130.

Pletikos, M., Sousa, A.M.M., Sedmak, G., Meyer, K.A., Zhu, Y., Cheng, F., Li, M., Kawasawa, Y.I., and Šestan, N. (2014). Temporal specification and bilaterality of human neocortical topographic gene expression. Neuron 81, 321-332.

Qin, M., Kang, J., Burlin, T.V., Jiang, C., and Smith, C.B. (2005). Postadolescent changes in regional cerebral protein synthesis: an in vivo study in the FMR1 null mouse. J Neurosci 25, 5087-5095.

Sato, D., Lionel, A.C., Leblond, C.S., Prasad, A., Pinto, D., Walker, S., O’Connor, I., Russell, C., Drmic, I.E., Hamdan, F.F., Michaud, J.L., Endris, V., Roeth, R., Delorme, R., Huguet, G., Leboyer, M., Rastam, M., Gillberg, C., Lathrop, M., Stavropoulos, D.J., Anagnostou, E., Weksberg, R., Fombonne, E., Zwaigenbaum, L., Fernandez, B.A., Roberts, W., Rappold, G.A., Marshall, C.R., Bourgeron, T., Szatmari, P., and Scherer, S.W. (2012). SHANK1 deletions in males with autism spectrum disorder. Am J Human Genets 90, 879-887.

Schutt, J., Falley, K., Richter, D., Kreienkamp, H.J., and Kindler, S. (2009). Fragile $\mathrm{X}$ mental retardation protein regulates the levels of scaffold proteins and glutamate receptors in postsynaptic densities. J Biol Chem 284, 25479-25487.

Sharma, A., Hoeffer, C.A., Takayasu, Y., Miyawaki, T., McBride, S.M., Klann, E., and Zukin, R.S. (2010). Dysregulation of mTOR signaling in fragile X syndrome. J Neurosci 30, 694-702.

Sharma, J., Mukherjee, D., Rao, S.N.R., Iyengar, S., Shankar, S.K., Satishchandra, P., and Jana, N.R. (2013). Neuronatin-mediated aberrant calcium signaling and endoplasmic reticulum stress underlie neuropathology in lafora disease. J Biol Chem 288, 9482-9490.

Sharma, J., Rao, S.N.R., Shankar, S.K., Satishchandra, P., and Jana, N.R. (2011). Lafora disease ubiquitin ligase malin promotes proteasomal degradation of neuronatin and regulates glycogen synthesis. Neurobiol Dis 44, 133-141.

Sheridan, S.D., Theriault, K.M., Reis, S.A., Zhou, F., Madison, J.M., Daheron, L., Loring, J.F., Haggarty, S.J., and Cookson, M.R. (2011). Epigenetic characterization of the FMRI gene and aberrant neurodevelopment in human induced pluripotent stem cell models of fragile $\mathrm{X}$ syndrome. PLoS ONE 6, e26203.

Sittler, A., Devys, D., Weber, C., and Mandel, J.L. (1996). Alternative splicing of exon 14 determines nuclear or cytoplasmic localisation of FMR1 protein isoforms. Human Mol Genets 5, 95-102.

Strumbos, J.G., Brown, M.R., Kronengold, J., Polley, D.B., and Kaczmarek, L.K. (2010). Fragile $\mathrm{X}$ mental retardation protein is required for rapid ex- perience-dependent regulation of the potassium channel Kv3.1b. J Neurosci 30, 10263-10271

Surendran, S., Tyring, S.K., and Matalon, R. (2005). Expression of calpastatin, minopontin, NIPSNAP1, rabaptin-5 and neuronatin in the phenylketonuria (PKU) mouse brain: possible role on cognitive defect seen in PKU. Neurochem Int 46, 595-599.

Tapper, W., Collins, A., Gibson, J., Maniatis, N., Ennis, S., and Morton, N.E. (2005). A map of the human genome in linkage disequilibrium units. Proc Natl Acad Sci USA 102, 11835-11839.

Telias, M., Segal, M., and Ben-Yosef, D. (2013). Neural differentiation of fragile $\mathrm{X}$ human embryonic stem cells reveals abnormal patterns of development despite successful neurogenesis. Dev Biol 374, 32-45.

The Dutch-Belgian Fragile X Consorthium, C.E.B., and Coleta Verheij, Rob Willemsen. (Willems 1994). Fmrl knockout mice: a model to study fragile X mental retardation. Cell 78, 23-33.

Trapnell, C., Roberts, A., Goff, L., Pertea, G., Kim, D., Kelley, D.R., Pimentel, H., Salzberg, S.L., Rinn, J.L., and Pachter, L. (2012). Differential gene and transcript expression analysis of RNA-seq experiments with TopHat and Cufflinks. Nat Protoc 7, 562-578.

Vaquerizas, J.M., Kummerfeld, S.K., Teichmann, S.A., and Luscombe, N.M. (2009). A census of human transcription factors: function, expression and evolution. Nat Rev Genet 10, 252-263.

Warde-Farley, D., Donaldson, S.L., Comes, O., Zuberi, K., Badrawi, R., Chao, P., Franz, M., Grouios, C., Kazi, F., Lopes, C.T., Maitland, A., Mostafavi, S., Montojo, J., Shao, Q., Wright, G., Bader, G.D., and Morris, Q. (2010). The GeneMANIA prediction server: biological network integration for gene prioritization and predicting gene function. Nucleic Acids Res 38, W214-W220.

Westmark, C.J., Westmark, P.R., O’Riordan, K.J., Ray, B.C., Hervey, C.M., Salamat, M.S., Abozeid, S.H., Stein, K.M., Stodola, L.A., Tranfaglia, M., Burger, C., Berry-Kravis, E.M., Malter, J.S., and Ferreira, S.T. (2011). Reversal of fragile X phenotypes by manipulation of AbPP/Ab levels in Fmrl ${ }^{\mathrm{KO}}$ mice. PLoS ONE 6, e26549.

Wu, H., Xu, J., Pang, Z.P., Ge, W., Kim, K.J., Blanchi, B., Chen, C., Sudhof, T.C., and Sun, Y.E. (2007). Integrative genomic and functional analyses reveal neuronal subtype differentiation bias in human embryonic stem cell lines. Proc Natl Acad Sci USA 104, 13821-13826.

Zang, J.B., Nosyreva, E.D., Spencer, C.M., Volk, L.J., Musunuru, K., Zhong, R., Stone, E.F., Yuva-Paylor, L.A., Huber, K.M., Paylor, R., Darnell, J.C., Darnell, R.B., and Cox, G.A. (2009). A mouse model of the human fragile X syndrome I304N mutation. PLoS Genet 5, e1000758.

Zhang, X.Q., and Zhang, S.C. (2010). Differentiation of neural precursors and dopaminergic neurons from human embryonic stem cells. Methods Mol Biol 584, 355-366.

Zheng, S., Chou, A.H., Jimenez, A.L., Khodadadi, O., Son, S., Melega, W.P., and Howard, B.D. (2002). The fetal and neonatal brain protein neuronatin protects PC12 cells against certain types of toxic insult. Dev Brain Res 136, 101-110.

Open Access This article is distributed under the terms of the Creative Commons Attribution License which permits any use, distribution, and reproduction in any medium, provided the original author(s) and source are credited.

\section{SUPPORTING INFORMATION}

Figure S1 HDF2-iPSC (A) and FXS-iPSC (B) were tested with Asuragen Amplide FMR1 PCR Kit.

Figure $\mathbf{S 2}$ Venn diagram summarizing the number of DE genes.

Table S1 Number of differentially expressed genes at each stage

Table S2 Real-time RT-PCR primers

Table S3 Reads count of the RNA-seq data

The supporting information is available online at life.scichina.com and link.springer.com. The supporting materials are published as submitted, without typesetting or editing. The responsibility for scientific accuracy and content remains entirely with the authors. 